\title{
Emergency analgesia in the paediatric population. Part II Pharmacological methods of pain relief
}

\section{S C Maurice, J J O'Donnell, T F Beattie}

Emerg Med J 2002;19:101-105

The first paper in this series examined some of the reasons for poor provision of analgesia to children in accident and emergency departments. In this paper we discuss the pharmacological agents available for systemic and local administration in the management of children's pain in the emergency environment.

\section{LOCAL ANAESTHETIC}

Local anaesthesia provides a simple, cheap, and relatively safe adjunct to manage children's pain in the accident and emergency (A\&E) department. It has the advantage that with appropriate training and supervision, most techniques can be performed by a junior A\&E doctor. A major disadvantage of local anaesthesia is the pain and fear associated with injection, although this can be minimised by applying the anaesthetic topically or by using warmed, buffered lignocaine (lidocaine) for injection. ${ }^{1-5}$ Pain can also be reduced by using a narrow gauge needle and giving the injection slowly. As with any procedure in children, it is essential to take the time to explain the procedure fully to both parent and child, in a manner appropriate to the child's age and understanding.

\section{Topical anaesthesia}

Local anaesthetic cream can be applied to the skin before venepuncture or cannulation, if the child's condition allows time for this. Eutectic mixture of local anaesthetics (EMLA-registered trade mark; Astra) contains $2.5 \%$ lignocaine and $2.5 \%$ prilocaine. It is applied in a thick layer and sealed under an occlusive dressing for 45-60 minutes. An alternative topical anaesthetic is Ametop (registered trade mark; S\&N Hlth), which contains $4 \%$ amethocaine. It has a slightly faster rate of onset (30-40 minutes), a longer duration of action and causes local vasodilatation, which may aid cannulation..$^{7-9}$ EMLA is contraindicated in infants under 1 year, and Ametop is not recommended for use in infants under 1 month of age. Neither EMLA nor Ametop should be applied to mucous membranes or open wounds as rapid absorption may result in systemic toxicity. This makes them unsuitable for use in wounds requiring cleaning or suturing.

Alternative preparations can be used to anaesDr S C Maurice, Accident and Emergency Department, Wythenshawe Hospital, Southmoor Road, Wythenshawe, Manchester, M23 9LT, UK; sue.maurice@ gw.smuht.nwest.nhs.uk thetise open wounds for cleaning and suturing, and are becoming more readily available in the UK in doses suitable for children. ${ }^{10}$ TAC, which is often used in the USA is a mixture of tetracaine, adrenaline (epinephrine), and cocaine and can be applied to the wound on gauze. TAC can be prepared in several formulations, but tetracaine $1 \%(10 \mathrm{mg} / \mathrm{ml})$, adrenaline $1: 4000(250 \mu \mathrm{g} / \mathrm{ml})$, and cocaine $4.0 \%(40 \mathrm{mg} / \mathrm{ml})$ is effective and carries less risk of toxicity than more concentrated formulations. Both cocaine and tetracaine are potentially toxic and in the concentration described above, the maximum dose of $1.5 \mathrm{ml}$ of TAC per $\mathrm{kg}$ of body weight should not be exceeded. TAC should not be used on mucous membranes or where there is a risk of distal ischaemia because of the vasoconstrictor properties of adrenaline. ${ }^{11-14}$ Although not currently available in the UK, TAC can be made up at request in local pharmacies.

\section{Local infiltration}

Local infiltration is the anaesthetic technique most commonly used in the A\&E department to provide anaesthesia for suturing children's wounds. Suturing can be kept to a minimum by using alternatives such as skin adhesive or paper skin closures whenever possible as long as the cosmetic result is not inferior. ${ }^{15}$ One per cent lignocaine $(10 \mathrm{mg} / \mathrm{ml})$ is the most commonly used concentration for local anaesthesia at a maximum dose of $3 \mathrm{mg} / \mathrm{kg}$. The lignocaine is injected subcutaneously through the wound edges at the site of the sensory nerve endings unless the wound is dirty or infected. It is important to take care when infiltrating the wound edges that they do not become distorted as this can prevent good cosmetic wound closure. The anaesthetic takes effect in 2-4 minutes and lasts approximately 20 minutes. Inhaled nitrous oxide during infiltration can make the procedure more acceptable to children. If the child is not able to tolerate the planned procedure under local anaesthetic, it may be preferable to perform the procedure under general anaesthetic.

\section{Field block}

A field block may be used to drain a small abscess or clean an infected wound. Local infiltration is less effective in areas of infection as the increased acidity of the tissues reduces the anaesthetic effect and the increased vascularity around the infected tissues speeds up absorption of the anaesthetic agent into the systemic circulation. ${ }^{16}$ This reduces the duration of anaesthesia and can lead to toxicity. Injecting into an infected area is also extremely painful and risks spreading the infection. Use of a field block greatly reduces the likelihood of these adverse reactions as the anaesthetic is infiltrated at a point slightly distant from the infected tissues based on the principle that branches of sensory nerves run parallel to the skin surface in the subcutaneous tissues. The 
anaesthetic is injected around the perimeter of the wound or abscess approximately $1 \mathrm{~cm}$ away from its edge using a maximum dose of $3 \mathrm{mg} / \mathrm{kg}$ of lignocaine. The block may take 2-3 minutes longer to have effect than local infiltration. The efficacy of anaesthesia can be enhanced by using lignocaine with adrenaline to cause local vasoconstriction, thus prolonging the duration of anaesthesia at the operative site. Adrenaline should only be used where there is no risk of causing distal ischaemia. A field block is also useful for areas difficult to infiltrate anatomically, such as the ear. ${ }^{16}{ }^{17}$

\section{Peripheral nerve block}

This technique involves injection of local anaesthetic in the region of a peripheral nerve to provide anaesthesia to the area supplied by that nerve. Bupivacaine is a longer acting anaesthetic than lignocaine and is often used for nerve blocks at a concentration of $0.25 \%(2.5 \mathrm{mg} / \mathrm{ml})$ with an upper limit of $2 \mathrm{mg} / \mathrm{kg}$ in children. The most commonly used blocks in children are femoral and digital nerve blocks, but other peripheral nerve blocks are also very useful.

\section{Femoral nerve block}

This gives excellent anaesthesia for a fractured shaft of femur. The block should be inserted before radiography or application of a traction splint. Bupivacaine ( $2 \mathrm{mg} / \mathrm{kg}$ ) is most often used. It has a slower onset but longer duration of action than lignocaine. The femoral artery is identified, half way between the pubic tubercle and the anterior superior iliac spine. The anaesthetic is injected just lateral to the artery in a fan shape around the femoral nerve. Palpation of the femoral artery and aspiration before injection reduces the risk of an intra-arterial injection. ${ }^{17} 18$

\section{Digital nerve block}

This can be used for minor procedures such as replacing an avulsed finger nail or draining a paronychia. Adrenaline should not be used with the anaesthetic as this can cause digital ischaemia. Half to one millilitre of $1 \%$ plain lignocaine is injected on each side of the base of the finger adjacent to the neurovascular bundle. The exact volume of anaesthetic used depends on the size of the child, but should not be such as to cause compression of the digital vessels and swelling of the digit. Aspiration before injection reduces the risk of intravascular injection. The block will usually take effect in 5-10 minutes and last for up to an hour, by which time oral analgesia can be given to minimise further discomfort. ${ }^{17}$

Other peripheral nerve blocks including auricular, facial, wrist, and ankle blocks can be useful in the A\&E setting, but their description is beyond the scope of this review. ${ }^{16-18}$

\section{Complications of local anaesthesia}

Complications of local anaesthesia include systemic toxicity, anaphylactic reactions, local damage with bruising, haematoma formation, nerve injury and needle breakage.

Systemic toxicity occurs when the blood concentration of local anaesthetic exceeds the toxic level, leading to significant amounts reaching the brain and myocardium. This may be attributable to too high a dosage being administered, too rapid infiltration, inadvertent intravascular injection or application of the anaesthetic to an open wound or infected area resulting in rapid absorption. Symptoms of toxicity are neurological and cardiovascular. Early symptoms of toxicity are tingling around the mouth, tinnitus, slurred speech, and dizziness. These may progress to confusion, convulsions, coma, hypotension, and arrhythmias. If toxicity to local anaesthetic is suspected administration of the anaesthetic should stop immediately. The patient should be moved to a resuscitation area and the resuscitation principles of "Airway, Breathing, Circulation" applied. Convulsions may be treated with small, incremental doses of diazepam. Hypotension should be treated by laying the patient flat, gaining secure intravenous access and giving fluid resuscitation. Cardiac arrhythmias usually resolve spontaneously, but bradycardia may require treatment with atropine if cardiac output is affected. When local anaesthetics are used with appropriate care and dose calculation, toxic reactions are rare, but resuscitation equipment and expertise should always be readily available..$^{16-19}$

Anaphylactic reactions to local anaesthetics are rare, but should be treated as for any anaphylactic reaction. ${ }^{20}$

A further common complication of local anaesthesia is a failed block. The patient should always be believed if they say the anaesthetic is not working. Common causes of a failed block are not leaving enough time for the block to take effect, siting the injection too far from the nerve and giving insufficient dose of anaesthetic. ${ }^{16}$

\section{ANALGESIC AGENTS}

The ideal analgesic has the following features:

- easily and painlessly administered

- rapid onset of action

- predictable, effective analgesic properties

- no side effects

- cheap

\section{Route of administration}

The route by which a drug is administered determines its bioavailability and rate of onset of action. Oral analgesics can be administered painlessly with high levels of acceptability to the child but have a more delayed onset of action and variable absorption compared with intravenous administration. Rectal administration is painless, with reliable rapid absorption, and is usually well tolerated in children. ${ }^{21}$ There are however, only a limited number of drugs are available in a rectal preparation in the UK and they are relatively expensive. Also, some parents prefer their children not to be given rectal medication.

The intravenous route provides the most reliable and controllable method for relief of pain despite the need for cannula insertion. Intravenous administration allows for careful titration of the analgesic agent against response to provide effective pain relief, minimise toxic effects, and allow top up doses as required. ${ }^{22}$

The intramuscular route is not suitable for paediatric analgesia in the A\&E department.

Intramuscular injections are painful, absorption is unpredictable, onset of action is slow, and top up doses require further painful injections. ${ }^{23}{ }^{24}$ In a hypovolaemic patient peripheral vasoconstriction will reduce muscle and skin blood flow, with the result that much of an intramuscular dose will remain at the site of injection and the child will receive little immediate benefit. After fluid resuscitation, systemic absorption may lead to an unpredictable bolus absorption of the drug. ${ }^{22}$

Drugs are absorbed across the nasal mucosa more reliably than with oral administration and the use of diamorphine and fentanyl intranasally is an alternative route. Recent studies have been encouraging. ${ }^{25}$

\section{Mild analgesics (table 1)}

Paracetamol

Paracetamol is an excellent analgesic for mild pain..$^{27}$ It can be given orally in a dose of $15 \mathrm{mg} / \mathrm{kg} \mathrm{4}-6$ hourly, to a maximum of four doses in 24 hours. A rectal preparation is also available. Paracetamol has analgesic and antipyretic properties but it is not an anti-inflammatory agent. It acts centrally as a cyclo-oxygenase inhibitor.

Aspirin

Aspirin is a cheaper drug than paracetamol and is as effective an analgesic, reducing pain through prostaglandin inhibition. 
Table 1 Mild analgesics

\begin{tabular}{|c|c|c|c|c|c|c|}
\hline & Dose/route & Analgesic & Antipyretic & $\begin{array}{l}\text { Anti- } \\
\text { inflammatory }\end{array}$ & $\begin{array}{l}\text { Approximate } \\
\text { cost (one dose } \\
\text { to } 20 \mathrm{~kg} \text { child)* }\end{array}$ & Comments \\
\hline Paracetamol & $\begin{array}{l}15 \mathrm{mg} / \mathrm{kg} ; 4-6 \text { hrly } \\
\text { Max } 4 \text { doses } / 24 \mathrm{hrs} \\
\text { oral or rectal }\end{array}$ & yes & yes & no & $\begin{array}{l}\text { oral; } 5 p \\
\text { rectal; } £ 2.30\end{array}$ & Avoid in liver disease \\
\hline Ibuprofen & $\begin{array}{l}20 \mathrm{mg} / \mathrm{kg} \text { daily in 3-4 } \\
\text { divided doses } \\
\text { oral }\end{array}$ & yes & yes & yes & $10 p$ & $\begin{array}{l}\text { Less side effects than other NSAIDs, but less } \\
\text { anti-inflammatory action } \\
\text { *See below }\end{array}$ \\
\hline Diclofenac & $\begin{array}{l}1-3 \mathrm{mg} / \mathrm{kg} \text { daily in } 2-3 \\
\text { divided doses }\end{array}$ & yes & yes & yes & oral; $4 p$ & *Avoid in asthma and under 12 months \\
\hline
\end{tabular}

\begin{tabular}{|c|c|c|c|c|c|c|}
\hline & Route & Dose & $\begin{array}{l}\text { Analgesic } \\
\text { potency }\end{array}$ & $\begin{array}{l}\text { Respiratory } \\
\text { depression }\end{array}$ & $\begin{array}{l}\text { Approximate } \\
\text { cost (one dose } \\
\text { to } 20 \mathrm{~kg} \text { child)* }\end{array}$ & Comments \\
\hline Codeine & oral & $1 \mathrm{mg} / \mathrm{kg} ; 4-6$ hrly & $\begin{array}{l}\text { mild-moderate } \\
\text { pain }\end{array}$ & + & $5 p$ & $\begin{array}{l}\text { Not advised IV: risk of histamine release and } \\
\text { anaphylaxis }\end{array}$ \\
\hline \multirow[t]{2}{*}{ Morphine } & oral/rectal & $\begin{array}{l}0.2-0.4 \mathrm{mg} / \mathrm{kg} \\
\text { prn, } 4 \text { hrly }\end{array}$ & severe nain & & $\begin{array}{l}\text { oral; } 9 p \\
\text { rectal; } 50 p\end{array}$ & $\begin{array}{l}\text { poor oral bioavailability; nausea; anxiolytic } \\
\text { Slow IV bolus; titrate against response }\end{array}$ \\
\hline & IV & $\begin{array}{l}0.1-0.2 \mathrm{mg} / \mathrm{kg} \\
\text { prn, } 4 \text { hrly }\end{array}$ & severe pain & ++ & IV; 60p & \\
\hline \multirow[t]{2}{*}{ Diamorphine } & IV & $\begin{array}{l}0.08 \mathrm{mg} / \mathrm{kg} \\
\text { prn } 4 \mathrm{hrly}\end{array}$ & & & $\mathrm{IV} ; £ 1.10$ & $\begin{array}{l}\text { shorter duration of action than morphine; less } \\
\text { nausea }\end{array}$ \\
\hline & oral & $\begin{array}{l}0.1-0.2 \mathrm{mg} / \mathrm{kg} \\
\text { prn } 4 \text { hrly }\end{array}$ & severe pain & ++ & oral; $12 p$ & \\
\hline Fentanyl & IV & $3-5 \mathrm{mcg} / \mathrm{kg}$ & severe pain & +++ & $24 p$ & rapid onset, short acting \\
\hline Pethidine & $\begin{array}{l}\text { IV } \\
\text { oral }\end{array}$ & $\begin{array}{l}0.5-1.0 \mathrm{mg} / \mathrm{k} \\
0.5-2.0 \mathrm{mg} / \mathrm{kg}\end{array}$ & moderate pain & ++ & $\begin{array}{l}\text { IV; } 10 p \\
\text { oral; } 5 p\end{array}$ & $\begin{array}{l}\text { Short duration of action } \\
\text { Nausea }\end{array}$ \\
\hline
\end{tabular}

It has been associated with Reye's syndrome when used to treat varicella or influenza and therefore should not be used in children under 12 years. ${ }^{28}$ Aspirin can also cause gastrointestinal irritation, bronchospasm, and reduced platelet function.

\section{Other non-steroidal anti-inflammatory agents}

Drugs such as ibuprofen have gained popularity for mild to moderate pain especially when the pain is attributable to musculoskeletal trauma in children. They act by peripheral inhibition of prostaglandins. They are analgesic, antipyretic, and anti-inflammatory and have the advantage of a longer duration of action than aspirin or paracetamol. They can induce bronchospasm in children with asthma and are contraindicated if there is a history of gastrointestinal bleeding or renal impairment.

Ibuprofen is given orally in a dose of $5 \mathrm{mg} / \mathrm{kg}$ and can be given 6-8 hourly. It is not recommended for children under 1 year or weighing less than $7 \mathrm{~kg}$. Both paracetamol and ibuprofen are available in liquid form making them suitable for use in young children. Diclofenac is available in suppository form, which is useful for children who are vomiting. ${ }^{1926} 29$ The dose is $1 \mathrm{mg} / \mathrm{kg} 8-12$ hourly.

\section{Nitrous oxide}

This is inhaled as a mixture with oxygen usually at 50/50 ratio causing analgesia, amnesia, and a dissociative state. ${ }^{30}$ It has a good analgesic effect within 3-4 minutes, wearing off approximately five minutes after inhalation of the gas has stopped. $^{31}$

Nitrous oxide in a $70 \%$ mixture with $30 \%$ oxygen has been shown to be more effective than EMLA in providing anxiolysis and analgesia for paediatric venous cannulation. ${ }^{32}$ Administration is painless and children as young as 3-4 years can control administration themselves. The use of a mouthpiece can encourage children frightened by the face mask to inhale the gas. Nitrous oxide must be delivered by a failsafe system, which shuts off if oxygen flow is obstructed.

Nitrous oxide has the disadvantage that it is absorbed into and causes expansion of gas filled spaces, so an alternative analgesic should be used if pneumothorax, bowel obstruction or head injury are suspected..$^{22}$ It is valuable for use in the prehospital setting and for short procedures such as dressings, splint application or cannula insertion. Nitrous oxide is an underused method of analgesia in children.

\section{Moderate/strong analgesics Opioids (table 2) \\ Codeine}

This is a mild opioid drug useful even in young children to control mild to moderate pain. The oral dose is $1 \mathrm{mg} / \mathrm{kg}$ every four to six hours. Intravenous administration is not recommended as it can cause profound hypotension, probably because of histamine release. ${ }^{33}$ Combined with paracetamol, codeine has a small additive effect and can be used when stronger pain relief is needed. ${ }^{34-36}$ Like other opioids codeine can cause nausea, vomiting, respiratory depression, and constipation, but these side effects are rare when used appropriately.

\section{Morphine}

Morphine is an excellent drug for treating severe pain resulting from burns, fractures, and other injuries. ${ }^{23}$ It produces analgesia by inhibiting synaptic transmission of opioid receptors in the brain. If morphine is titrated intravenously over $2-3$ minutes at a dose of $0.1-0.2 \mathrm{mg} / \mathrm{kg}$ the side effects of respiratory depression, hypotension, and nausea are rare. ${ }^{37}$ The intravenous route is preferable as onset of analgesia is rapid and 
titration allows an appropriate analgesic dose to be given without causing unwanted side effects. If a child is awake, alert and in pain, morphine can be safely titrated against response, as long as the patient is closely monitored, preferably with pulse oximetry and frequent blood pressure measurements. ${ }^{38-40}$

An alternative route of administration is orally, which is often more acceptable to children $(0.2-0.4 \mathrm{mg} / \mathrm{kg})$. However, morphine is unreliably absorbed from the gastrointestinal tract because of high first pass metabolism resulting in delayed, unpredictable onset of action.

It is safe to discharge a child home after one dose of morphine, providing the child fulfills discharge criteria (see section on discharge criteria below). Antiemetics are rarely needed with opioids in children if used as described above.

\section{Diamorphine}

This is an alternative to morphine at a dose of $0.04-0.08 \mathrm{mg} / \mathrm{kg}$ intravenously. Recent trials using intranasal diamorphine at $0.1 \mathrm{mg} / \mathrm{kg}$ have so far shown this to be an effective, safe, and acceptable method of analgesia in children with isolated long bone fractures. ${ }^{25}$

\section{Pethidine}

Pethidine at a dose $0.5-1 \mathrm{mg} / \mathrm{kg}$ intravenously is an alternative opioid analgesic. It has a shorter duration of action than morphine and less sedative effects. It has the disadvantage of causing nausea and vomiting, anxiety, tremors, disorientation and even convulsions in some patients when used intravenously..$^{23}$ Morphine is a better choice for severe pain in children.

\section{Fentanyl}

Fentanyl is a newer synthetic opioid given at a dose of 3-5 $\mu \mathrm{g} / \mathrm{kg}$ intravenously over 3-5 minutes, followed by incremental doses of $1 \mu \mathrm{g} / \mathrm{kg}$ as required. ${ }^{41}$ It can also be given intranasally. It has a rapid onset of action and a short duration of action of 30-40 minutes. It rarely causes hypotension, possibly because it causes less histamine release than morphine. However, it may cause respiratory depression, which lasts longer than the analgesic effect especially in combination with other sedatives and analgesics. ${ }^{112}$

A rare side effect of fentanyl when high doses or rapid infusion are used $(>15 \mu \mathrm{g} / \mathrm{kg})$ is neuromuscular block causing severe thoracic and abdominal muscle rigidity, which may make ventilation difficult. Naloxone may reverse this effect but sometimes a paralysing agent is required. Because of these features of fentanyl, it should only be used by doctors with anaesthetic training and should not be used in high doses in the A\&E department.

\section{Ketamine}

Ketamine is a phencyclidine derivative that binds to opioid receptors. It effectively produces analgesia, anaesthesia, and a dissociative state but has several side effects. ${ }^{23}$

It is sympathomimetic and increases heart rate, blood pressure and cerebral oxygen demand. It is contraindicated in patients with raised intracranial pressure as it is a cerebral vasodilator. It produces copious secretions that may induce laryngospasm, necessitating use of an antisialogogue.

Vivid dreams and hallucinations are associated with ketamine and can be attenuated by the prior administration of a benzodiazepine. Intravenously a dose of $0.5-1.0 \mathrm{mg} / \mathrm{kg}$ will produce light sedation in a child for approximately 10 minutes. Alternatively an oral dose of $5-10 \mathrm{mg} / \mathrm{kg}$ will produce a similar but slightly longer lasting effect. ${ }^{114}$

\section{MONITORING AND DISCHARGE}

All children given analgesic drugs with potentially sedating effects should undergo brief assessment before drug administration. Ideally base line observations performed should
Suggested departmental protocol for paediatric analgesia

\section{Mild pain}

Paracetamol $15 \mathrm{mg} / \mathrm{kg} \mathrm{4-6}$ hourly, orally (maximum of four doses in 24 hours)

Ibuprofen $5 \mathrm{mg} / \mathrm{kg}$ 6-8hourly, orally (avoid in asthmatics, children under $7 \mathrm{~kg}$ and under 1 year)

\section{Moderate pain}

Codeine $1 \mathrm{mg} / \mathrm{kg}$ 4-6hourly, orally (use with paracetamol for mild synergistic effect)

\section{Severe pain}

Morphine $0.1-0.2 \mathrm{mg} / \mathrm{kg}$ IV 3-4 hourly (mMaximum of six doses in 24 hours)

Oramorph $0.2-0.4 \mathrm{mg} / \mathrm{kg}$ 3-4 hourly, orally (if IV access not readily available, maximum of six doses in 24 hours)

1 Offer analgesia to every child with pain.

2 Estimate the child's pain score as objectively as possible and select appropriate analgesia.

3 Perform observations of pulse, respiratory rate, oxygen saturation, blood pressure, and conscious level if giving morphine or oramorph.

4 Weigh the child and calculate dose of drug in $\mathrm{mg} / \mathrm{kg}$. Use chart or formula (age +4 ) to calculate weight where physical weighing is impossible. ${ }^{44}$

5 Document the drug given with dose, route and time. 6 Document the effectiveness of analgesia at 15 minute intervals - that is, repeat the pain score, and give further analgesia as required. Observations should also be repeated as appropriate to monitor the patient's general condition.

include conscious level, pulse rate, oxygen saturation, respiratory rate, blood pressure, and pain score. ${ }^{21}$ It is inadvisable to give sedating analgesic drugs to children who have a reduced conscious level, unless a full anaesthetic is required and is given by appropriately anaesthetic trained staff. Documentation of the drug given should include time and route of administration. After administration, observations should be repeated at least every half hour.

\section{Discharge criteria}

If the child is to be sent home they should fulfill the following criteria before discharge into the care of a parent or responsible adult:

I The child can sit unaided and hold up head (infant), or stand and walk unaided (child).

2 The child has regained pre-analgesia observations of respiratory rate, conscious level, and oxygen saturation.

3 The child remains in the A\&E department for at least one hour after administration of the analgesic.

4 The supervising adult receives a full explanation and advice sheet and understands it. Ideally this should be signed and countersigned.

5 The child has been prescribed appropriate analgesia to take home.

Only when all five criteria are met can the child be safely discharged home. It is helpful to provide the parent or guardian with a discharge advice sheet.

\section{THE FUTURE}

Some ways forward are presented. Firstly, education regarding the various methods available would increase the staff's repertoire of analgesia skills. This may take the form of tutorials, handouts, and individual teaching. It is also important to lead by example and to demonstrate to the more junior members of staff that management of paediatric pain takes a high priority in patient care. 
Secondly, protocols for pain assessment and analgesia should be drawn up and displayed in poster form throughout the department (see box)

Thirdly, audit can raise awareness of A\&E doctors and nurses of the need for better provision of pain relief for children. Ongoing audit cycles can determine the adequacy of analgesia provided in each department and highlight particular areas for improvement.

Finally, empowering nursing staff to recognise those children who require analgesia and to prescribe simple analgesia could be a powerful tool. Legislation may be required to allow this but would be welcomed by many.

\section{SUMMARY}

In this paper we have discussed the pharmacological options available for paediatric pain relief in the A\&E department. Effective analgesic and anaesthetic agents should be given in adequate dose and by appropriate route for the type and level of pain suffered.

\section{Contributors}

SCM undertook the initial literature review and completed the first draft of the paper. JJO'D contributed to the literature review, discussed the core ideas and edited the paper. TFB developed the original idea, led discussions on the topics to be studied and co-ordinated the series of papers. TFB is the guarantor for the paper.

\section{Authors' affiliations}

S C Maurice, Accident and Emergency Department, Wythenshawe Hospital, Manchester, UK

T F Beattie, J J O'Donnell, Accident and Emergency Department, Royal Hospital for Sick Children, Edinburgh, UK

\section{REFERENCES}

1 Barffield JM, Ford DT, Homer PJ. Buffered versus plain lignocaine for digital nerve blocks. Ann Emerg Med 1993;22:216-19.

2 Brogan GX, Giarrusso E, Hollander JE, et al. Comparison of plain, warmed and buffered lidocaine for anesthesia of traumatic wounds. Ann Emerg Med 1995;26:121-6.

3 Cornelius P, Kendall J, Meek S, et al. Alkalinisation of lignocaine to reduce the pain of digital nerve block. J Accid Emerg Med 1996; 13:339-40.

4 Waldbillig DK, Quinn JV, Stiell IG, et al. Randomised double-blind controlled trial comparing room temperature and heated lidocaine for digital nerve block. Ann Emerg Med 1995;26:677-81

5 Mader TJ, Playe SJ, Garb JL. Reducing the pain of local anesthetic infiltration: warming and buffering have a synergistic effect. Ann Emerg Med 1994;23:550-4

6 Maunuksela E, Korpelar L. Double blind evaluation of a lidocaine-prilocaine cream (EMLA) in children. Br J Anaesth 1986;58:1242-5.

7 Lawson RA, Smart NG, Gudgeon AC, et al. Evaluation of an amethocaine gel preparation for percutaneous analgesia before venous cannulation in children. Br J Anaesth 1995;75:282-5.

8 Woolfson AD, McCafferty DF, Boston V. Clinical experiences with a novel percutaneous amethocaine preparation: prevention of pain during venepuncture in children. Br J Clin Pharmacol 1990;30:273-9.

9 Beardsall K, Cunningham S, Riley K. Pick the best option to control child pain. Hospital Doctor 1997;23 Oct:52

10 Kendall JM, Charters A, McCabe SE. Topical anaesthesia for children's lacerations: an acceptable approach? J Accid Emerg Med 1996;13:119-22.

11 Badgwell JM. Anesthesia and analgesia for minor injuries to children. Int Anesthesiol Clin 1994;32:123-47.
12 Bonadio WA Wagner VR. Adrenaline-cocaine gel topical anesthetic for dermal laceration repair in children. Ann Emerg Med 1992;21:1435-8.

13 Grant SAD, Hoffman RS. Use of tetracaine, epinephrine and cocaine as a topical anaesthetic in the emergency department. Ann Emerg Med 1992;21:987-97.

14 Schilling CG, Bank DE, Borchert BA, et al. Tetracaine, epinephrine and cocaine (TAC) versus lidocaine, epinephrine and tetracaine (LET) for anesthesia of lacerations in children. Ann Emerg Med 1995;25:203-8.

15 Quinn JV, Drzewiecki A, Li MM, et al. A randomized, controlled trial comparing a tissue adhesive with suturing in the repair of pediatric facial lacerations. Ann Emerg Med 1993;22:1 130-5.

16 Illingworth KA, Simpson KH. Anaesthesia and analgesia in emergency medicine. Oxford: Oxford University Press, 1998.

17 Eriksson E, ed. Illustrated handbook of local anaesthesia. Copenhagen: AB Astra, 1969

18 Aitkenhead AR, Smith G. Textbook of anaesthesia. 3rd edn. Edinburgh: Churchill Livingstone, 1996.

19 BMA/ RPSGB. British National Formulary. London: British Medical Association and Royal Pharmaceutical Society of Great Britain, March, 1999.

20 Project Team of the Resuscitation Council (UK). Emergency medical treatment of anaphylactic reactions J Accid Emerg Med 1999;16:243-7.

21 Sacchetti A, Schafermeyer R, Gerardi M, et al. Pediatric analgesia and sedation. Ann Emerg Med 1994;23:237-50.

22 Macrae WA, Davies HT. Pain from acute trauma. Prescribers' Journal 1993:333:232-7.

23 Selbst SM. Analgesia in children: Why is it underused in emergency departments? Drug Safety 1992;7:8-13.

24 Aronson JK. Routes of drug administration: intramuscular injection. Prescribers' Journal 1995;35:32-7

25 Wilson JA, Kendall JM, Cornelius P. Intranasal diamorphine for paediatric analgesia: assessment of safety and efficacy. J Accid Emerg Med 1997:14:70-2.

26 Alder Hey Hospital. Alder Hey book of children's doses. 6th edn. Manchester: 1994 (with amendments 1996)

27 Selbst SM, Henretig FM. The treatment of pain in the emergency department. Pediatr Clin N Am 1989;36:965-78.

28 Weinberger $M$. Analgesic sensitivity in children with asthma. Paediatrics 1978;62:910-15.

29 Ducharme J. Emergency pain management: A Canadian Association of Emergency Physicians (CAEP) Document. J Emerg Med 1994:12:855-66.

30 Flomenbaum N, Gallagher EJ, Eagen K. Self-administered nitrous oxide: an adjunct analgesic. J Am Coll Emerg Phys 1979;8:95-7.

31 Gamis AS, Knapp JF, Glenski JA. Nitrous oxide analgesia in a pediatric emergency department. Ann Emerg Med 1989;18:177-81.

32 Vetter TR. A comparison of EMLA cream versus nitrous oxide for pediatric venous cannulation. J Clin Anesth 1995;7:486-90.

33 Shanahan EC, Marshall AG, Garrett CPO. Adverse reactions to intravenous codeine phosphate in children. Anaesthesia 1983;38:40-3.

34 de Craen AJM, Di Giulio G, Lampe-Schoenmaeckers AJEM, et al. Analgesic efficacy and safety of paracetamol-codeine combinations versus paracetamol alone; a systematic review. BM 1996:313:321-5.

35 Beaver WT. Combination analgesics. Am J Med 1984;77:38-53.

36 Field HL. Neurophysiology of pain and pain modulation. J Med 1984;77:2-7.

37 Woolard DJ, Terndrup TE. Sedative-analgesic agent administration in children: analysis of use and complications in the emergency department. J Emerg Med 1994;12:453-61.

38 Selbst SM, Clark M. Analgesic use in the emergency department. Ann Emerg Med 1990;19:1010-13.

39 Hughes WT, Buescher ES. Preparation of the patient. In: Pediatric procedures. Philadelphia: WB Saunders, 1980.

40 Paris PM, Stewart RD. Narcotic analgesics: the pure agonists. In: Pain management in emergency medicine. West Hartford: Appleton-Lange, 1987.

41 Billmire DA, Neale HW, Gregory RO. Use of fentanyl in the outpatient treatment of pediatric facial trauma. J Trauma 1985;25:1080-5.

42 Chudnofsky CR, Wright SW, Donen SC. The safety of fentanyl use in the emergency department. Ann Emerg Med 1989;18:635-9.

43 Qureshi FA, Mellis PT, McFadden MA. Efficacy of oral ketamine for providing sedation and analgesia to children requiring laceration repair. Pediatr Emerg Care 1995;11:93-7.

44 Advanced Life Support Group. Advanced paediatric life support: the practical approach. 2nd edn. London: BM Publishing Group, 1997. 